\title{
Marie Rennotte: educadora ilustrada, feminista revolucionária, médica dos desvalidos
}

\author{
Marie Rennotte: illustrated educator, revolutionary feminist, \\ doctor of the underprivileged \\ Marie Rennotte: educadora ilustrada, feminista revolucionaria, \\ doctora de los desfavorecidos
}

Peri Mesquida (iDa

\section{Resumo}

A luta no Brasil pela emancipação feminina, pelos direitos básicos da mulher à educação, à igualdade, à liberdade, teve em Jeanne Françoise Joséphine Marie Rennotte, nascida em 1852 em Wandre, Província de Liège, na Bélgica, uma incansável batalhadora, mas pouco lembrada pela historiografia que trata das mulheres no Brasil. Este artigo originado de uma pesquisa documental e bibliográfica procura trazer à luz um pouco da vida e da obra incansável batalhadora em favor da educação da mulher, dos seus direitos, e também do seu engajamento em favor dos desvalidos e das desvalidas por meio da prática da medicina social, objeto da sua tese de revalidação do diploma de graduação em medicina obtido no Woman's Medical College da Pennsylvania, Estados Unidos da América, em 1893.

Palavras-chave: Educação da mulher Direitos das mulheres. Medicina social.

\begin{abstract}
The struggle in Brazil for women's emancipation, for women's basic rights to education, for equality, for freedom in Brazil, found in Jeanne Françoise Joséphine Marie Rennotte, born 1852 in Wandre, Liège Province, Belgium, a infatigable battler, but little remembered by the women's historiography in Brazil. This article, originated from a documentary and bibliographical research, seeks to bring to light some of the life and work of this tireless worker in favor of the education of women, of their rights, and also of their engagement in favor of the underprivilegeds through practice of social medicine, object of his thesis of
\end{abstract}

\footnotetext{
a Pontifícia Universidade Católica do Paraná, Curitiba, PR, Brasil. Doutor em Ciências da Educação, e-mail: mesquida.peri@gmail.com
} 
revalidation of the diploma of graduation in medicine obtained in the Woman's Medical College of Pennsylvania, United States of America, in 1893.

Keywords: Women's education. Women's rights. Social medicine.

\section{Resumen}

La lucha en Brasil por la emancipación femenina, por los derechos básicos de las mujeres a la educación, la igualdad y la libertad, tuvo en Jeanne Françoise Joséphine Marie Rennotte, nacida en 1852 en Wandre, Provincia de Liège, Bélgica, una incansable luchadora, pero poco recordada por la historiografía que trata sobre las mujeres en Brasil. Este artículo, originado a partir de una investigación documental y bibliográfica, busca sacar a la luz un poco de la vida y el trabajo de este incansable luchadora a favor de la educación de las mujeres, sus derechos y también su compromiso en favor de los desfavorecidos y desfavorecidas a través de la práctica de la medicina social, objeto de su tesis de revalidación de la licenciatura en medicina obtenida en el Woman's Medical College de Pennsylvania, Estados Unidos de América, en 1893.

Palabras clave: Educación de la mujer. Derechos de la mujer. Medicina social

\section{Introdução}

A ebulição política e social na Europa na segunda metade do século XIX, com a Comuna de Paris (1868), a Unificação da Alemanha (1871), as Guerras francoprussiana (1870) e austro-prussiana (1866), entre outros movimentos, como a Unificação da Itália (1848 e 1868), causava apreensão quanto a futuro da juventude europeia e alimentava sonhos de aventura e vida melhor fora do Velho do Continente.

No Brasil, a concepção liberal de mundo ganhava adeptos, mesmo entre os quadros da monarquia, levando os políticos de dentro e de fora dos gabinetes do Império, a anteverem o fim da escravidão e a instauração do sistema de mão de obra assalariada. Ao mesmo tempo, iniciativas, em particular no oeste paulista, ainda no final da primeira metade do século XIX, tratavam da substituição de pessoas escravizadas por imigrantes, em especial vindos da Europa, como é o caso da Fazenda Ibicaba, de Nicolau Araujo Vergueiro, em Limeira (MESQUIDA, 1994).

$\mathrm{Na}$ segunda metade do século, o Ministro do Interior e Obras Públicas, Antonio Francisco de Paula Souza (1819-1866), juntamente a Aureliano Candido Tavares Bastos (1839-1875), fundou a Sociedade Internacional de Imigração cujo 
primeiro diretor foi Guilherme Scully, também editor do jornal propagandístico da imigração Anglo Brazilian Times, com a finalidade de sensibilizar por meio da publicidade a imigração de europeus, sobretudo anglo-saxões, leia-se norteamericanos. Portanto o Brasil, logo depois da interdição do tráfego de escravos (1850), abria as suas portas para imigrantes, com o objetivo de substituir a mão de obra de escravizados cuja oferta iria rarear, pela do "trabalhador livre". Seja para trabalhar nas fazendas de café como assalariado, ou "às terças" (trabalho servil), seja para atuar como preceptor, no caso dos letrados que se transferiam para o nosso país.

Thomas Davatz (1941), imigrante suíço, desenhou um mapa da educação brasileira na primeira metade do século XIX, na sua obra Memórias de um colono no Brazil (1850), mostrando o desinteresse do Estado pela ação educativa dos seus súditos, incluindo a falta de escolas, mesmo para a elite agrária. Daí a necessidade dos fazendeiros contratarem preceptoras e/ou preceptores estrangeiros para ensinarem suas filhas e filhos, incluindo nesse ensino, uma língua estrangeira, de preferência a língua francesa. Na realidade, a preceptoria como vemos no Emilio, on da educação, de Jean-Jacques Roussseau (1979), era uma prática comumente utilizada pelas famílias europeias abastadas nos séculos XVIII e XIX. Sophie Deroisin na obra Petites filles d'autrefois - 1750-1940 (1986), conta que nos jornais alemães, ingleses e franceses apareciam anúncios oferecendo emprego para "precepteurs capables d'enseigner les enfants, fils et filles" (DEROISIN, 1986, p. 118), tratando-se de uma forma encontrada pela aristocracia e a burguesia nascente na Europa, não somente de ensinar boas maneiras às meninas, mas, em especial, de educar as crianças de forma a absorverem as ideias iluministas e dos enciclopedistas franceses.

Gilberto Freyre, na obra Vida social no Brasil nos meados do século XIX (1964), escrevendo sobre a presença de preceptoras nas famílias da elite agrária brasileira, morando nas fazendas, ou na cidade, observa que se trata de uma prática originária da Europa que as famílias brasileiras abastadas passam a utilizar:

As preceptoras que as senhoras de engenho mais ortodoxamente patriarcais... anunciavam nos jornais, precisarem para encarregar-se do ensino, eram senhoras ou senhoritas estrangeiras, que soubessem iniciar as meninas no conhecimento da gramática, da música, do piano; e que também as instruísse no conhecimento da língua francesa (FREYRE, 1964, p. 68) 
Na segunda metade do século XIX, encontraremos em especial nas regiões em processo de desenvolvimento capitalista, do Vale do Paraíba e do oeste de São Paulo, a presença de preceptoras/professoras estrangeiras, geralmente, com sólida formação pedagógica, como foi o caso de Ina von Binzer/Ulla Von Eck, jovem alemã nascida em Lauenburg, em 1856, recebendo certificado de professora em Soest (Alemanha), cidade do Estado da Renânia do Norte-Vestfália. Aportou no Rio de Janeiro em 1881, com 25 anos de idade, indo atuar como preceptora, inicialmente em fazendas do Rio de Janeiro, como a do "Dr. Rameiro" (BINZER, 1994), depois em São Paulo, nas fazendas de famílias da oligarquia agrária paulista. Preceptora na fazenda de Martinho Prado Junior (que dava a seus filhos e filhas nomes latinos: Caio, Plínio, Cordélia, Clélia, Lavínia) teve experiências que a marcaram, pois quando retornou para Europa em 1884, escreveu uma obra, constituída de cartas que ela enviou para uma amiga alemã, verdadeiro legado histórico, sociológico e antropológico, com o título: Os meus romanos - alegrias e tristezas de uma educadora alemã no Brasil (1994).

\section{Marie Rennotte - Educadora: O iluminismo ilustrado pestalozziano no interior de São Paulo, no século XIX.}

O Rev. J. J. Ransom, missionário pioneiro da implantação definitiva do metodismo em terras brasileiras, desde sua chegada em 1875, pressionava a Junta de Missões da Igreja Metodista do Sul dos Estados Unidos a fundar um educandário no Brasil, pois para ele "aqui há uma porta aberta e um chamado, coisas que os metodistas amam por tradição... Atualmente as portas estão abertas à educação" (RAMSOM, 1881, p. 97). No relatório de 23 de fevereiro de 1882, ele anuncia ter feito contato com uma dama, a qual ele acreditava ser francesa "que chega até nós com as melhores recomendações; as nossas perspectivas são boas” (RANSOM, 1882b, p. 2). No Nashville Christian Advocate, de março de 1882, Ramson escreve dizendo que depois de contatos com "Miss Leslie, proprietária do Colégio Progresso, conseguimos a cessão de Mlle. Rennotte, fluente em alemão, francês, inglês e com ótimo domínio da língua portuguesa e sólida formação na pedagogia moderna, para auxiliar Miss Watts, no Colégio Piracicabano" (RAMSON, 1883, p. 3). Trata-se de Marie Rennotte, 
professora belga que veio para o Brasil em 1878 como preceptora para trabalhar em fazendas no Rio de Janeiro, mas passou rapidamente a atuar na docência em instituições de ensino, como o Colégio de Anna Werneck, de Engenho Novo, e o Colégio Progresso, este uma referência de ensino e método pedagógico, onde Rui Barbosa pôde observar a prática do ensino proposta por ele em seu relatório sobre a instrução pública, de 1881(JOHNSON, 1977).

$\mathrm{Na}$ realidade, Ransom, o missionário metodista, tinha razão. Mlle. Rennotte, convidada a deixar o Rio de Janeiro e ir para o interior de São Paulo, trazia na bagagem não somente os diplomas do Cours Normaux, Societé pour l'Instrucion Élementare, de 1874, e o Brevet de Capacité pour l'enseignement - Institutrice IIème ordre (Paris), de 1875, certificados de sua capacidade docente, encontrados, entre outros documentos, como seu passaporte belga e carta de recomendação de proficiência em francês e alemão emitida pelo Bildungsinstitut Grossherzogliches, de Mannheim (Instituto de Educação do Grande Ducado de Mannheim) no Dossier número 1, do Instituto Histórico e Geográfico de São Paulo (MESQUIDA, 1994, p. 233).

No Colégio Piracicabano, para onde foi em fevereiro de 1882 a professora belga de olhos acinzentados e 1,60 m de altura (dados do passaporte), mostrou na prática sua "solida formação moderna", lecionando francês, geografia, música, ciências naturais, botânica, e montando laboratórios de física, química e biologia, onde as(os) alunas(os) aprendiam fazendo as "lições de coisas", nos passos de Rousseau e Pestalozzi, como atesta a Gazeta de Piracicaba, de 17 de dezembro de 1882, comentando a sessão de exames públicos realizada pelo Colégio Piracicabano no final do ano letivo:

\footnotetext{
Sinceramente louvamos o científico e apaixonado método de Mlle. Rennotte que não se satisfazendo com respostas vagas e superficiais, persiste na sua pergunta e as reiterando, força o espírito a trabalhar e dar por este modo uma resposta completa, justa e clara... $\mathrm{Na}$ história natural, as plantas, as flores e os animais são seus pupilos naturais...concorda Mlle. Rennotte (GAZETA DE PIRACICABA, 17/12, 1882, p. 1).
}

Marie Rennotte trouxe, pois para o Colégio Piracicabano, na região oeste de São Paulo, ideias iluministas, dos enciclopedistas franceses e dos precursores da escola nova, como o protestante suíço Johan Heinrich Pestalozzi, destacando a importância da pesquisa científica, pelo método da observação e da experimentação, com as lições 
de coisas de Pestalozzi, como assinala o artigo que escreveu no jornal Gazeta de Piracicaba, referindo-se à química e à ciência de modo geral:

Esta sciencia, outrora unicamente praticada nos esconderijos dos conventos, envolvida nos segredos tornando deste modo mysteriosos seus adeptos, não é mais hoje a arte de transmutar os metaes, não se intitula mais o - Eureka da Imortalidade -. Mais humilde em seus desejos, mais séria em seus intentos, a sciencia de hoje, pondo-nos em contacto immediato com a natureza, prova, com a balança na mão, o erro da doutrina antiga e proclama este princípio fundamental: nada se perde, nada se crea. Applicada à medicina legal, a Toxicologia, fundamento da farmacologia, a chimica sem procurar nem produzir a "Panacée" (remédio capaz de curar todos os males), o elixir vital, derrama sobre a humanidade seus benefícios de tal maneira, que é excusado realçar seu valor. (GAZETA DE PIRACICABA, 11 out. 1887).

Mlle. Rennotte desenvolveu no Colégio Piracicabano as ideias pedagógicas de Rousseau e Pestalozzi, como destaca o jornal Gazeta de Piracicaba, esclarecendo que nesse educandário, se verifica um "ensino prático aplicado às coisas da vida" (GAZETA DE PIRACICABA, 28/12/1883), mas também as dos enciclopedistas franceses, em particular as de Marie Jean Antoine Nicolas de Caritat, Marquês de Condorcet (1743-1794). Introduz no ensino para as meninas aulas de ciências naturais, uma inovação no Brasil, e defende a coeducação dos sexos, seguindo o pensamento pedagógico de Condorcet (1994) expresso no seu projeto de reforma da Instrução pública na França, de 1891, intitulado Cinq mémoires sur l’instruction publique.

Inova ao introduzir no Colégio Piracicabano as sessões públicas de exames, convidando pessoas da sociedade piracicabana (como os irmãos Moraes Barros, Prudente e Manoel, respectivamente futuros governador do Estado de São Paulo/Presidente da República e senador) para avaliarem as alunas nas diversas disciplinas, um verdadeiro "festival" enciclopédico, como descreve o professor Omparet na Gazeta de Piracicaba:

No dia 11 do corrente, às 10 horas, em espaçosa sala achava-se reunida uma escolhida sociedade constituída de elegantíssimas senhoras e de cavaleiros distintos. Estavam presentes os srs. Dr. P. de Moraes Barros e dr. M. Moraes Barros...A não querermos passar por falso apreciador, forçoso é dizer alguma cousa a respeito do exame de Physica no qual arguiu com a distincta professora, Mlle. Rennotte, a sua esperançosa alumna, a Senhora d. A.M. de Barros. Louvamos o scientifico e aperfeiçoado método...À noite, foram encenadas a comédia francesa Le Chat e a peça Le Bourgeois Gentilhomme, antecipadas pelo canto arrebatador da Marseillaise, sob a direção de Mlle. Rennotte (GAZETA DE PIRACICABA, 17/12/1882, p. 1 e 2) 
Marie Rennotte publicou inúmeros artigos na Gazeta de Piracicaba e n'A Provincia, de São Paulo, jornal que nasceu com o nome de $A$ República, fundado em 03 de dezembro de 1870 pelo Clube Republicano, trazendo no seu primeiro número o Manifesto Republicano. A República circulou até 1874, tendo então sido substituído pelo jornal A Provincia (mais tarde passou a se chamar O Estado de São Paulo). Nos seus artigos, Mlle. Rennotte era porta-voz do Colégio Piracicabano, escrevendo matérias polêmicas para a época sobre a educação, a educação da mulher, defendendo a "instrução" que era veiculada pelo Colégio:

\begin{abstract}
A mulher, é bem triste dizê-lo, é de alguma sorte tratada abaixo da sua dignidade, observada, em algumas relações, como um ser que nada pode, para não dizer completamente nullo. Esta injustiça continuou através dos séculos... e um bom número acredita ainda que na mulher a matéria tem primazia sobre a inteligência. Apoiando-se sobre esse sofisma recusaram iniciar a mulher em todas as carreiras... Entretanto não obstante as cadeias que se quis sobrecarregar o pensamento da mulher, vemos essa faísca divina vencendo os obstinados que se lhe opunham e, nesses tempos obscuros em que o homem orgulha-se de não saber assinar o seu nome, vemo-la à altura de poetas, taes como Marie de France, Marguerite de Valois, e outras que hoje, se medem à altura dos gigantes da ciência (GAZETA DE PIRACICABA, 23/08/1882, p.1).
\end{abstract}

Em 1883, já tendo aderido à confissão metodista, Mlle. Rennotte rebateu as críticas feitas pelas irmãs de São José ao conteúdo e ao método pedagógico empregado no Colégio Piracicabano, as desafiando a "estabelecer entre as alunas dos dois colégios (Piracicabano e Assumpção) concursos", para pôr em "evidência as habilitações respectivas dos dois métodos de ensino” (RENNOTTE, in Gazeta de Piracicaba, 28/01/1883, p. 2). As irmãs não aceitaram o "convite" de Rennotte, e somente se estabeleceram definitivamente na cidade dez anos depois, em 1893, quando a professora Belga se encontrava nos Estados Unidos concluindo o curso de medicina.

Em outro artigo, escrevendo sobre o Colégio Piracicabano como uma instituição educativa diferenciada, ela chama a atenção dos pais e mães que atentem para a educação das suas filhas, dizendo:

Paes e mães que sois muitas vezes injustos sobre o que toca à educação de vossas filhas. Sabei que importa a sua felicidade e a de sua familia, por em jogo quando não lhes derdes instrução ou fizerdes disto objeto de pouco preço. Procuremos, pois para a mulher os meios de instruir-se, facilitemos em vez de obstruir, os caminhos abruptos da ciência (GAZETA DE PIRACICABA, 30/08/1882, p. 1). 
Marie Rennotte insiste com as famílias piracicabanas a confiarem nas suas filhas, pois as "mulheres são tão capazes quanto os homens de desenvolverem projetos e propostas científicas"; precisam somente que se libertem das "cadeias" que inibem sua criatividade. Portanto, "não embaracemos que a mulher desenvolva a ciência e a cultura... Incitemos a mulher a estudar" (GAZETA DE PIRACICABA, 10/12/1882, p. 1).

A ação pedagógica inovadora desenvolvida por Mlle. Rennotte no Colégio Piracicabano, recebida como membro da Igreja Metodista em 16/09/1883, colaborou para a construção de uma base educacional sólida que levaria as autoridades republicanas, ao assumirem o poder, a desejarem, nas reformas da instrução, seguir o método, as metodologias e a prática pedagógica do Piracicabano, como afirma Antenor Calanducci, redator-chefe da Revista Atualidades Pedagógicas, da editora Civilização Brasileira, cujos diretores eram Ary da Matta e Ênio da Silveira:

Ao ponto de merecer de um dos maiores homens do Brasil de então, Prudente de Moraes, homem de ideias largas, espírito adiantado, confiar ao Colégio Piracicabano a educação de seus filhos... De tal modo a pedagogia praticada naquele educandário impressionou o estadista inesquecível que ele a aproveitou para o leit-motiv da reforma da instrução do Estado de São Paulo que ele teve ocasião de iniciar, como governador do Estado de São Paulo, auxiliado por Caetano de Campos, em 1992. Ali ele pode ver e apreciar as aplicações da moderna pedagogia (CALANDUCCI, 1953, p. 18-23).

Não se pode negar que a formação europeia de Marie Rennotte, herdeira do genebrino Jean-Jacques Rousseau e dos protestantes alemão e suíço, Froebel e Pestalozzi, do iluminismo e da Enciclopédia, foi a responsável direta pela implantação e consolidação do Colégio Piracicabano, assim como da expansão da sua prática pedagógica e do seu método de ensino, influenciando reformas, como a reforma da escola normal de São Paulo, iniciada por Caetano de Campos, em 1892 e que se estendeu até 1894, como acabamos de ver. Defendendo uma educação integral, “mente, coração e ação" (“tête, coeur, main”) (PESTALOZZI, 2008), à luz do método pestalozziano de saber aprender, saber sentir, saber fazer; da necessidade da sociedade brasileira se dar conta de que já está a mais de 100 anos do "século chamado das luzes e do progresso" e ainda não tomou consciência da "importância da ciência e da instrução das mulheres, procuremos, pois para a mulher os meios de instruir-se; 
facilitemos em vez de obstruir os caminhos abruptos da sciencia" (RENNOTE, in Gazeta de Piracicaba, 30/08,1882).

A luta de Marie Rennotte em favor da instrução da mulher, da sua liberdade e do direito do voto, é o tema do próximo capítulo deste artigo.

\section{A Metodista Marie Rennote e o feminismo ilustrado revolucionário no Brasil dos séculos XIX e XX}

Como vimos no capítulo anterior, a formação pedagógica de Marie Rennotte foi feita em Paris na segunda metade do século XIX, sob a égide de um movimento feminista reivindicando liberdade, justiça e igualdade para as mulheres. Se a Declaração dos Direitos do Homem e do Cidadão, de 26 de agosto de 1789, fazendo ecoar a ideia iluminista dos direitos humanos que chegara até os enciclopedistas franceses, não tocava na questão da igualdade de homens e mulheres, no âmbito da liberdade e da justiça, as mulheres teriam que reagir. E o fizeram: Olympe de Gouges redige e publica em uma brochura os Direitos da Mulher e da Cidadã, endereçando a Rainha Maria Antonieta, em 05 de setembro de 1791, com a intenção de apresentá-la também à Assembleia Legislativa Constituinte em outubro do mesmo ano.

Olympe de Gouges esclarece logo no primeiro artigo da Declaração (GOUGES, 2003) que "a mulher nasce livre e permanece igual ao homem em direitos". Segue mostrando que "o objetivo de toda associação política é a conservação dos direitos naturais e imprescritíveis da mulher e do homem. Esses direitos são: a liberdade, a prosperidade, a segurança e sobre tudo, a resistência à opressão" (Art. 2). Defende o direito da mulher à liberdade e à justiça (Art. 4); no posfácio da Declaração, ironiza ao reivindicar o direito à educação, escrevendo: “como se trata neste momento de uma educação nacional, veremos se nossos sábios Legisladores irão pensar na educação da mulher” (GOUGES, 2003).

A arguta estudante belga em Paris não poderia ter deixado de tomar conhecimento também da obra da inglesa Mary Wollstonecraft (1792), Vindication of the rights of woman - with structures on political and moral subjects, cujo título expressa a luta das mulheres europeias pela igualdade de direitos, liberdade, justiça e educação 
publicada em 1792. No Brasil foi traduzida comentada e publicada na forma de artigos em revistas e jornais de Recife em 1833 pela brasileira Nísia Floresta (1989), autora do livro Direitos das mulheres e injustiças dos homens). O conteúdo da obra de Wollstonecraft (1792) não ficou alheio as reflexões dos socialistas utópicos franceses, como Henri de Saint-Simon (2012) e Charles Fourier (1848), ambos defendendo a igualdade entre os sexos como condição sine qua non para a construção de uma sociedade de liberdade e justiça (Charles Fourier criou o neologismo "féminisme").

Chegando ao Brasil percebe que "a mulher, é bem triste dizê-lo, é de alguma sorte tratada abaixo da sua dignidade, observada em algumas relações, como um ser que nada pode, para não dizer completamente nullo e oprimida" (RENNOTTE, Gazeta de Piracicaba, 20/08/1882, p. 1). Aproveita as páginas dos jornais para desfechar uma cruzada em favor da igualdade, da justiça e da liberdade da mulher, colocando a educação (instrução) como meio privilegiado para a obtenção desses direitos. Começa publicando uma série de artigos na Gazeta de Piracicaba com o título "Mulher e Liberdade". Ao introduzir o primeiro deles cita um pensamento de Voltaire: "A sociedade sem liberdade é um suplício", e vai adiante, escrevendo:

\begin{abstract}
Vou abrir um parênteses para explicar o que se entende por liberdade...creio que o seu sentido mais próprio é "condição do ser que não pertence a nenhum senhor"...toda ação traz consigo a ideia de responsabilidade de um autor. Ora, a mulher fazendo parte na constituição da humanidade assume, por conseguinte tanta responsabilidade como o homem perante a sociedade, e portanto deve gozar dos mesmos direitos, da mesma liberdade...o homem não tem uma só faculdade que a mulher não possua. Se o homem possue a razão, a mulher possue igualmente; a memória não falta à mulher. A vontade, quem não pode duvidar que ella não a tenha? (GAZETA DE PIRACICABA, 31/10/1883)
\end{abstract}

Os requisitos básicos para que a mulher conquiste os seus direitos são, para Mlle. Rennotte, a autonomia e o sentimento de que não "pertence a nenhum senhor". Essa tomada de consciência virá necessariamente pela educação, uma verdadeira força motriz que insere a mulher na sociedade como aquela que age em favor da justiça e da igualdade, valores inerentes à democracia. Por isso Marie Rennotte inicia um dos seus artigos com as palavras de Balzac: "o futuro das nações está entre as mãos das mães de família”. E acrescenta:

Eu não venho reclamar para a mulher senão a posição que lhe convém; senão o lugar que Ihe é devido, senão a dignidade à qual ella tem direito: a de agir. $E$ isso ocorre quando ela tem acesso à instrução. Procuremos pois para a mulher os meios de instruir-se; 
facilitemos-lhe em vez de obstruir os caminhos abruptos da sciencia (GAZETA DE PIRACICABA, 30/08/1882, p. 1).

Em 1885 Mlle. Rennotte embarca de férias para os Estados Unidos, juntamente a sua amiga, a diretora do Colégio Piracicabano, a missionária metodista Miss Martha H. Watts. Viajam por alguns estados, como Kentucky, Louisiana e Pensilvânia. Martha Watts retorna ao Brasil em 1886 e Mlle. Rennotte vai a Paris trazendo na bagagem no seu retorno, em 1887, segundo Gambiaghi (1984), material didático-pedagógico para auxiliar nas aulas de ciências naturais. Continua escrevendo artigos feministas na Gazeta de Piracicaba, bem como em jornais consagrados à causa do feminismo, como A Família, fundado em 1881 por Josefina Alvares de Azevedo, e em $A$ Mensageira, destacando a relação entre conquista de direitos e da liberdade da mulher, acentuando a importância da educação: “É triste dizel-o, o Brazil é uma das nações que ainda não compreendeu que a sua felicidade ou desgraça, progresso ou decadência provêem da boa ou má educação da mulher" (GAZETA DE PIRACICABA, 11/10/1887, p. 1). No A Mensageira, escreve: “A mulher é uma força social. Mostro pela física que a força da mulher pode impulsionar a marcha para o progresso da nação. Mas, para isso ela precisa ser instruída" (RENNOTTE, A Mensageira, $n^{\circ} 9.1897$, p. 87).

Sua luta em favor da causa da igualdade, dos direitos e da emancipação feminina, a levou a se engajar na luta política pelo direito de voto da mulher, como expressão de cidadania e de participação ativa na sociedade, tendo sido eleita em 1922, vice-presidente da Aliança Paulista pelo Sufrágio Feminino. Intelectual orgânica, com vimos, foi ainda, a primeira mulher a ser recebida como sócia titular do Instituto Histórico de São Paulo em 1904.

\section{Marie Rennotte: a medicina a serviço dos desvalidos}

O retorno de Mlle. Rennotte à Piracicaba foi marcado por homenagens. Teve uma "festiva recepção, presentes os alunos, amigos, o corpo docente, entre palmas e aclamação" (WOMAN'S MISSIONARY ADVOCATE, 1887, p. 4). Reiniciou imediatamente suas aulas de ciências naturais, agora, com material de laboratório 
trazido da França. Contudo a vocação da professora belga parece que se inclinava também para outra área: o corpo, em especial o corpo das mulheres desvalidas, colocando em prática o lema latino mens sana in corpore sano, de acordo com a formação que as missionárias metodistas recebiam no Peadbody College, em Nashville, Tennesse (MESQUIDA, 1994). O Nashville Christian Advocate, comentando as férias das duas “missionárias”, Miss Watts e Mlle. Rennotte, deixa antever o futuro desta última, aludindo às viagens que ambas faziam pelos Estados Unidos, inclusive na Pensilvânia onde visitaram instituições de ensino dos quakers (NASHVILLE CHRISTIAN ADVOCATE, 08/12/1885, p. 6). Provavelmente naquela ocasião começava a ser selado o futuro profissional de Marie Rennotte: a medicina, pois três anos mais tarde ela seria recebida pelo Woman’s Medical College of Pennsylvania, na Filadélfia, para cursar ciências médicas naquela instituição, precisamente no ano em que o College formava em medicina a primeira mulher nascida nos Estados Unidos, Susan La Flesche Picotte, e era dirigido pela Dra. Clara Marshall, com ótimas relações com os metodistas. O Woman's Medical College foi fundado dois anos depois que a convenção Seneca Falls, Nova York (1850), instituiu a garantia dos direitos das mulheres de se educarem e exercerem uma profissão, a partir do questionamento do metodista Bartholomew Fussell: “por que as mulheres não podem ter as mesmas oportunidades que os homens na vida?” (MANDELL, 2016).

É provável que o curso de medicina e a permanência de Marie Rennotte no Woman's Medical College, tenham sido financiados pela Woman's Missionary Society of the Methodist Episcopal Church, South, pois ela, como vimos, fora recebida em 1883, como membro da Methodist Episcopal Church, South, no Brasil (Piracicaba). No entanto, o que temos são somente indícios desta hipótese, pois não encontramos documentos que claramente a comprovem.

Ao concluir o curso de medicina em 1893, Mlle. Rennotte vai a Paris especializar-se em ginecologia e obstetrícia. Retornando ao Brasil no final daquele ano, iniciou o exercício da medicina em São Paulo, mesmo antes de obter a convalidação do diploma, o que ocorreu em março de 1895, com a tese Influência da educação da mulher sobre a medicina social, apresentada à Faculdade de Medicina e Farmácia do Rio de Janeiro. Na tese, mostra que mesmo sendo médica, não esquece a educação, pois não somente defende a prática de uma medicina voltada para os menos 
favorecidos como uma ação que a mulher médica realizaria como crítica a educação recebida pela mulher no Brasil, apelando para que seja feita uma reforma da educação. Critica o fato que "as jovens senhoras deixarão os bancos da escola com as cabeças cheias de datas e sem terem exercitado jamais suas faculdades de reflexão" (RENNOT'TE, 1895, p. 28), e apela:

Em nome da mulher, a favor da sociedade e em benefício da nação, peço vossa benévola intervenção na reforma de um ensino que concorre para fazer de vossos filhos cretinos, de vossos irmãos raquíticos, de vossas filhas espectros, fantasmas e meros fonógrafos sob o ponto de vista intelectual (RENNOTTE, 1895, p. 42).

Marie Rennotte foi a primeira médica em São Paulo a exercer a medicina na Santa Casa de Misericórdia da capital e dirigiu a Maternidade daquela instituição. Durante sua permanência na Santa Casa, dedicou-se à medicina social no sentido de atender os menos favorecidos, em especial mulheres e crianças. Pensando nas crianças pobres, iniciou uma campanha em 1912 para construir um hospital para crianças filhas de pais menos favorecidos, inaugurado em 1919 no bairro de Heliópolis, ali permanecendo até 1982.

A visita às casas dos enfermos, mulheres doentes ou gestantes, foi uma constante na vida ativa de Mlle. Rennotte, como destaca Maria Thereza C. Bernardes na obra Mulheres de ontem? Rio de Janeiro, século XIX (1988), a qual visitava, ou atendia de graça em seu consultório. Durante a epidemia de gripe espanhola, no período final da Primeira Guerra Mundial, atendeu ao apelo da Cruz Vermelha (seção da Cruz Vermelha Internacional que ela fundara em São Paulo) para ir cuidar de pacientes pobres em Dois Córregos, interior de São Paulo. O Jornal A Capital (11 de novembro de 1918, p. 2) indica que Marie Rennotte era Presidente da Sociedade de Medicina e Cirurgia de São Paulo e primeira presidente e participante ativa da Cruz Vermelha dando assistência às pessoas pobres.

Pela sua atividade na medicina social, fazendo do seu exercício uma verdadeira ação de cuidado do(a) outro(a), a doutora Marie Rennotte foi agraciada com a Cruz do Mérito concedida pela Alemanha no final da Primeira Guerra Mundial. 


\section{Considerações finais}

O percurso existencial de Jeanne Françoise Joséphine Marie Rennotte no Brasil que procuramos traçar neste artigo dedicado ao pioneirismo em tudo o que ela desenvolveu aqui, desde a educação, passando pela luta em favor dos direitos das mulheres, e sua obra filantrópica e de entrega ao cuidado dos menos favorecidos, está intimamente relacionado com suas ações em prol da justiça, da liberdade, da igualdade em um país no qual os "homens tudo podiam, e as mulheres, nada" (BINZER, 1994, p. 38). No campo da educação, Mlle. Rennotte trouxe para o interior de São Paulo ideias inovadoras de prática pedagógica que sensibilizaram os liberais, maçons e republicanos na sua luta pela mudança do regime na segunda metade do século XIX. Ideias como vimos, que inspiraram a reforma da Escola Normal de São Paulo, logo depois da proclamação da República (1892). A sua luta, primeiro, em favor da educação da mulher, depois, pela sua presença ativa na sociedade, incluindo o exercício da cidadania pela conquista do direito de votar e ser votada, como vicepresidente da Aliança Paulista pelo Sufrágio Feminino, ao lado da sua colega médica, Carlota Pereira de Queiroz, foi decisiva para que a efetivação do Decreto n. 21076, de 24 de fevereiro de 1932, assegurasse o direito do voto às mulheres de votar e serem votadas, apesar das restrições, pois esse direito somente poderia ser gozado pelas mulheres casadas que obtivessem a autorização dos maridos, assim como às viúvas e solteiras que tivessem renda própria. Essas restrições foram eliminadas na Constituição de 1934.

Contudo, Marie Rennotte foi sempre pedagoga, pelo exemplo e pelas ações; a educação, vocação primeira, a fez estudar e se engajar na luta em favor da "instrução" da mulher para que esta não somente conquistasse direitos, como também se dedicasse à educação de filhos e filhas, à luz do Manuel des mères, de Pestalozzi (1816). Mas a sua vocação segunda, o exercício da medicina, iniciada em 1893, levou a doutora Rennotte a se dedicar ao cuidado dos desvalidos, atendendo os "esfarrapados", intercedendo em seu favor junto às autoridades, e fundando instituições de cuidados médicos, como a Seção da Cruz Vermelha, o Hospital da Criança, Centros de Enfermagem, etc., além de participar ativamente de centros de pesquisa científica. 
Marie Rennotte: metodista, educadora, feminista, cuidadora dos desvalidos, verdadeira intelectual orgânica (GRAMSCI, 1975), faleceu em 1942, com 90 anos de idade tendo abraçado o Brasil como seu país de adoção existencial.

\section{Referências}

ANNUAL REPORT of the Brazil mission conference of the Methodist Episcopal Church, South. Nashville, TS, 1875 -1890. Nashville: Methodist Publishing House, s/d.

BERNARDES, M. T. C. C. Mulheres de ontem?: Rio de Janeiro, século XIX. São Paulo: Queiroz, 1988.

BINZER, I. V. Os meus romanos - alegrias e tristezas de uma educadora alemã no Brasil. Rio de Janeiro: Paz e Terra, 1994.

CALANDUCCI, A. Colégio Piracicabano: uma tradição e uma atualidade do ensino na “noiva da colina”. Atualidades Pedagógicas, São Paulo, ano IV, n. 22, p. 19, jul./ago. 1953.

CONDORCET, J.-A.-N. de C. Art Social. Sur l'admission des femmes au droit de cité. Journal de la Société, 1789, 3 juillet 1790, publié à Paris 1790.

CONDORCET, N. Cinq mémoires sur l'instruction publique. Paris: Garnier-Flammarion, 1994.

DAVATZ, T. Memórias de um colono no Brasil - 1850. São Paulo: Martins, 1941.

DEROISIN, S. Petittes filles d'autrefois - 1750-1940. Paris: Desclée de Brouwer, 1986.

FLORESTA, N. Direitos das mulheres e injustiças dos homens. São Paulo: Cortez, 1989.

FOURIER, C. Oeuvres complètes. Paris : La Librairie Sociétaire, 1848.

FREYRE, G. Vida social no Brasil nos meados do século XIX. Recife: Instituto Joaquim Nabuco, 1964.

GAMBIAGHI, O. Medicina em Piracicaba. Piracicaba: Degaspari, 1984.

GAZETA DE PIRACICABA, Anos pesquisados: 1882, 1883, 1887.

GAZETA DE PIRACICABA, Editorial. Mlle. Rennotte. 17/12/1882.

GOUGES, O. Déclaration des droits de la femme et de la citoyenne. Paris : Éditions Mille e Une Nuits, Fayard, 2003.

GRAMSCI, A. Quaderni del carcere. Torino : Einaudi, 1975.

JOHNSON, P. B. Rui Barbosa e a reforma educacional: lição de coisas. Rio de Janeiro: Fundação Casa Rui Barbosa, 1977.

JORNAL A CAPITAL,Doutora Rennotee. 11 de novembro de 1918 
MANDELL, M. Woman's Medical College of Pennsylvania. Rutgers: The State University of New Jersey, 2016.

MESQUIDA, P. Hegemonia norte-americana e educação protestante no Brasil. São Paulo: Editeo; Juiz de Fora: EDUFJF, 1994.

NASHVILLE CHRISTIAN ADVOCATE. Editorial, 1885.

PESTALOZZI, J. H. Écrits sur la méthode, Vl I. Le Mont-sur-Lausanne : Éditions Loisirs et Pédagogie, 2008.

RANSOM, J. J. Annual Report of the Brazil Mission Conference of the Episcopal Church, South, 1881.

RANSOM, J. J. Nashville Christian Advocate, march, 1882a.

RANSOM, John James. Woman's Missionary Advocate, may, 1882b.

RAMSON, J. J. Nashville Christian Advocate. September, 1883.

RENNOTTE, M. Influência da educação da mulher sobre a medicina social. Rio de Janeiro: Typographia Andina, 1895.

RENNOTTE, M. A mulher é uma força activa na sociedade. A mensageira. Vl. 1, nº 9, 1897. Imprensa Oficial do Estado da Cultura, São Paulo. Ed. Fac-Similar.

ROUSSEAU, J.-J. Emilio ou da educação. Rio de Janeiro: Difel, 1979.

SAINT-SIMON, H. Oeuvres complètes. Paris: PUF, 2012. 4 v.

WATTS, M. Woman's Missionary Advocate, june. 1887.

WOLLSTONECRAFT, M. Vindication of the rights of woman - with structures on political and moral subjects. London: Oxford Publishing House, 1792.

RECEBIDO: 04/09/2019

APROVADO: 30/10/2019
RECEIVED: 09/04/2019

APPROVED: $10 / 30 / 2019$
RECIBIDO: 04/09/2019

APROBADO: 30/10/2019 